\title{
A New DTC Scheme using Second Order Sliding Mode and Fuzzy Logic of a DFIG for Wind Turbine System
}

\author{
${ }^{1, *}$ Zinelaabidine BOUDJEMA \\ Department of Electrical Engineering \\ Laboratoire Génie Electrique et \\ Energies Renouvelables (LGEER), \\ University of Chlef, Hay Salem \\ 02000, Algeria
}

\author{
${ }^{2}$ Rachid TALEB \\ Department of Electrical Engineering \\ Laboratoire Génie Electrique et \\ Energies Renouvelables (LGEER), \\ University of Chlef, Hay Salem \\ 02000, Algeria
}

\author{
${ }^{3}$ Adil YAHDOU \\ Department of Electrical Engineering \\ Laboratoire Génie Electrique et \\ Energies Renouvelables \\ (LGEER), University of Chlef, Hay \\ Salem 02000, Algeria
}

\begin{abstract}
This article present a novel direct torque control (DTC) scheme using high order sliding mode (HOSM) and fuzzy logic of a doubly fed induction generator (DFIG) incorporated in a wind turbine system. Conventional direct torque control strategy (C-DTC) using hysteresis controllers presents considerable flux and torque undulations at steady state period. In order to ensure a robust DTC method for the DFIG-rotor side converter and reduce flux and torque ripples, a second order sliding mode (SOSM) technique based on super twisting algorithm and fuzzy logic is used in this paper. Simulation results show the efficiency of the proposed method of control especially on the quality of the provided power comparatively to a C-DTC.
\end{abstract}

Keywords-DFIG; wind turbine; DTC; SOSM; super twisting; fuzzy logic

\section{INTRODUCTION}

Among all kinds of renewable energy sources that are being developed recently in the world, wind energy source is the fastest growing one [1]. Currently, variable speed wind turbine system (WTS) employing DFIG is the most popular technology in presently installed wind turbines [2]. This is because DFIG presents many advantages compared to other generators used in WTSs such as reduced converter size, improved efficiency, and economic benefits [3].

Stator vector control with proportional-integral (PI) regulators is the usual strategy employed currently for WTS based on DFIG $[4,5]$. This strategy presents a good decoupling between the two current axes ( $d$ and $q$ ), therefore the model of the DFIG becomes simple and PI regulators can be employed. However, this method of control is highly depends on the accuracy of the machine parameters, employs diverse loops and needs a big regulation strength in order to ensures stability during the whole speed domain [6].

To avoid the disadvantages of the filed oriented control method, a novel DTC scheme has been discussed in this paper $[7,4]$. In the C-DTC strategy, torque and flux are directly regulated through switching table plus hysteresis regulators. However, some drawbacks brake the employ of these regulators, for example variable switching frequency and torque ripple [8,9]. In several research articles realized on DTC scheme, these undesirable problems are decreased by employing space vector modulation (SVM) technique, but the control robustness was immolated [10,11].

In recent years, sliding mode control (SMC) based on the theory of variable structure systems (VSS) has been extensively employed for nonlinear systems. It uses a particular version of on-off control, or discontinuous signal across the sliding surface, satisfying the sliding mode condition, to achieve a robust control. However, the SMC has a major inconvenience which is the chattering effect created by the discontinuous part of control. In order to resolve this problem, various adjustments to the usual control law have been discussed. The approach based on boundary layer is applied in almost all cases [12]. Another efficiency solution consists to substitute the discontinuous control signal by fuzzy logic one has also been used recently in some research works [13-15]. For the same goal the notion of HOSM control has also proven its competence in $[16,17]$ for different applications.

Some useful solutions for sliding mode DTC with small torque and flux undulations, applied for induction motor (IM) controls are presented in [18,19]. In [20], the authors suggest the using of a DTC with SOSM controllers employed to IM drive.

In the aim to design an advanced DTC with very small torque and flux undulations and without chattering effect, in our article we suggest to employ a new DTC scheme based on SOSM and fuzzy logic functions for a DFIG-based wind turbine. This is for essential objects, including reducing mechanical stresses and improving power quality provided to the grid. The SOSM technique generalizes the basic SMC design by integrating second order derivatives of the sliding variable [21]. A few of such controllers have been discussed in the literature [22-25].

The rest of the paper is arranged as follows. In section 2, the modeling of the DFIG-based WTS is presented. Section 3 provides the application of the SOSM-DTC scheme to the DFIG. In section 4 the novel SOSM-DTC strategy using on fuzzy logic algorithm is applied to the DFIG control. Section 5 discusses the simulation results to demonstrate the effectiveness of the proposed control strategy. 


\section{MODEL OF THE DFIG-BASED WTS}

\section{A. The WTS model}

Equation (1) gives the expression of the power captured by a WTS:

$$
P_{t}=\frac{1}{2} C_{P}(\lambda, \beta) R^{2} \rho v^{3}
$$

Where, $R, \rho, v, C_{P}, \lambda$ and $\beta$ are respectively: radius of the turbine $(\mathrm{m})$, air density $\left(\mathrm{kg} / \mathrm{m}^{3}\right)$, wind speed $(\mathrm{m} / \mathrm{s})$, the power coefficient, the tip speed ratio and blade pitch angle (deg).

The power coefficient $C_{p}$ is given as follows [26]:

$$
C_{P}=(0.5-0.167)(\beta-2) \sin \left[\frac{\pi(\lambda+0.1)}{18.5-0.3(\beta-2)}\right]-0.0018(\lambda-3)(\beta-2)
$$

With:

$$
\lambda=\frac{\Omega_{t} R}{v}
$$

Where, $\Omega_{t}$ is the wind turbine speed.

\section{B. Model of the DFIG}

The DFIG model in Park reference frame is given by [27,28]:

$$
\left\{\begin{array}{l}
V_{d s}=R_{s} I_{d s}+\frac{d}{d t} \psi_{d s}-\omega_{s} \psi_{q s} \\
V_{q s}=R_{s} I_{q s}+\frac{d}{d t} \psi_{q s}+\omega_{s} \psi_{d s} \\
V_{d r}=R_{r} I_{d r}+\frac{d}{d t} \psi_{d r}-\omega_{r} \psi_{q r} \\
V_{q r}=R_{r} I_{q r}+\frac{d}{d t} \psi_{q r}+\omega_{r} \psi_{d r}
\end{array},\left\{\begin{array}{l}
\psi_{d s}=L_{s} I_{d s}+M I_{d r} \\
\psi_{q s}=L_{s} I_{q s}+M I_{q r} \\
\psi_{d r}=L_{r} I_{d r}+M I_{d s} \\
\psi_{q r}=L_{r} I_{q r}+M I_{q s}
\end{array}\right.\right.
$$

Where $\left(V_{d s}, V_{q s}, V_{d r}, V_{q r}\right),\left(I_{d s}, I_{q s}, I_{d r}, I_{q r}\right),\left(\psi_{d s}, \psi_{q s}, \psi_{d r}, \psi_{q r}\right)$ are respectively the stator and rotor voltages, currents and fluxes, $R_{s}$ and $R_{r}$ are the resistances of the rotor and stator respectively, $L_{s}, L_{r}$ and $M$ are the inductance own stator, rotor, and the mutual inductance between two coils respectively.
The stator and rotor pulsations and rotor speed are interconnected by the following equation: $\omega_{s}=\omega+\omega_{r}$.

Where $\omega_{s}$ and $\omega_{r}$ are respectively the stator and rotor electrical pulsations, while $\omega$ is the mechanical one.

The mechanical equation of the DFIG is:

$$
C_{e m}=C_{r}+J \cdot \frac{d \Omega}{d t}+F_{r} \cdot \Omega
$$

Where we can express the electromagnetic torque $C_{e m}$ as follows:

$$
C_{e m}=\frac{3}{2} n_{p} \frac{M}{L_{s}}\left(\psi_{q s} I_{d r}-\psi_{d s} I_{q r}\right)
$$

Where $C_{r}, \Omega, J, F_{r}$ and $n_{p}$ are respectively: the load torque $(\mathrm{Nm})$, mechanical rotor speed $(\mathrm{rad} / \mathrm{s})$, the inertia $\left(\mathrm{kg} \cdot \mathrm{m}^{2}\right)$, the viscous friction $(\mathrm{Nm} / \mathrm{s})$ and the number of pole pairs.

The stator powers of the DFIG are defined as:

$$
\left\{\begin{array}{l}
P_{s}=\frac{3}{2}\left(V_{d s} I_{d s}+V_{q s} I_{q s}\right) \\
Q_{s}=\frac{3}{2}\left(V_{q s} I_{d s}-V_{d s} I_{q s}\right)
\end{array}\right.
$$

To obtain a decoupled control between the stator active and reactive powers, we use a $d q$ reference frame linked to the stator flux as shown in figure 1. Basing on equation (4) and supposing that the stator resistance can be neglected we can write:

$$
\begin{aligned}
& \psi_{d s}=\psi_{s} \text { and } \psi_{q s}=0 \\
& \left\{\begin{array}{l}
V_{d s}=0 \\
V_{q s}=\omega_{s} \psi_{s}
\end{array}\right. \\
& \left\{\begin{array}{l}
I_{d s}=-\frac{M}{L_{s}} I_{d r}+\frac{\psi_{s}}{L_{s}} \\
I_{q s}=-\frac{M}{L_{s}} I_{q r}
\end{array}\right.
\end{aligned}
$$

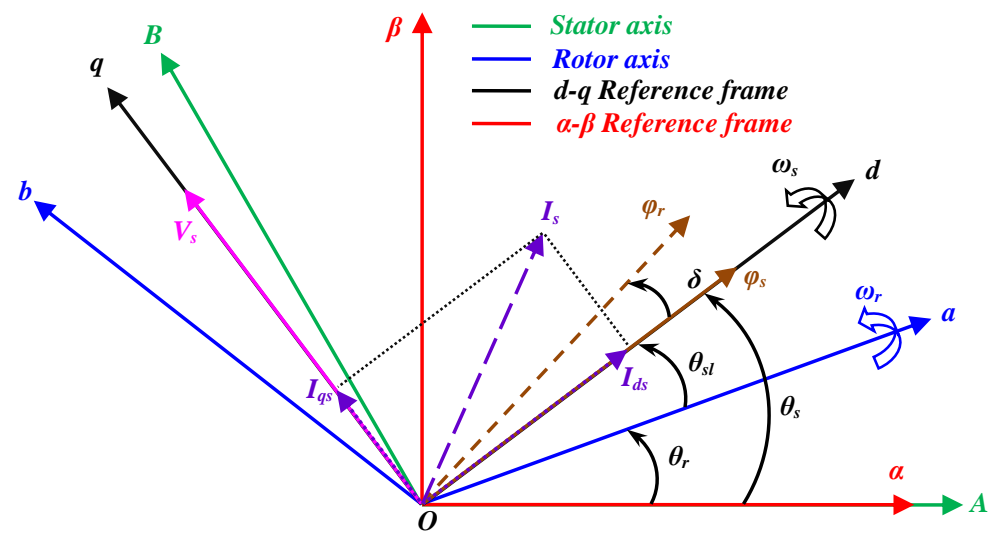

Fig. 1. Field oriented control technique 
By using (9) and (10), equations (6) and (7) can be written as follows:

$$
\left\{\begin{array}{c}
P_{s}=-\frac{3}{2} \frac{\omega_{s} \psi_{s} M}{L_{s}} I_{q r} \\
Q_{s}=-\frac{3}{2}\left(\frac{\omega_{s} \psi_{s} M}{L_{s}} I_{d r}-\frac{\omega_{s} \psi_{s}^{2}}{L_{s}}\right) \\
C_{e m}=-\frac{3}{2} n_{p} \frac{M}{L_{s}} I_{q r} \psi_{d s}
\end{array}\right.
$$

\section{SOSM-DTC OF DFIG}

The main objective of using SOSM-DTC is to develop a robust control of torque and rotor flux of the DFIG. In our system, the electromagnetic torque and flux are respectively controlled by $V_{d r}$ and $V_{q r}$.

Chattering effect which is a serious problem that exists in the conventional SMC can be very hurtful for the DFIG because it can create some undesirable phenomenon such as torque pulsation, current harmonics and acoustic noise, etc [29]. To relieve the influence of this problem, various solutions have been proposed [30, 31]. HOSM is one of the solutions proposed recently to eliminate the effect of this problem. This control method can ensure eradication of this undesirable phenomenon because it can acts on the sliding surface and its $1^{\text {st }}$ derivative ( $S=\dot{S}=0$ ) $[17,32]$. On the other hand, to retain the main advantages of the usual method, they debate the chattering phenomenon and offer advanced precision in practice. In the last decade many research works have applied this type of control [22, 23].

The big problem that accompanies the HOSM control executions is the increased required information. Indeed, it's

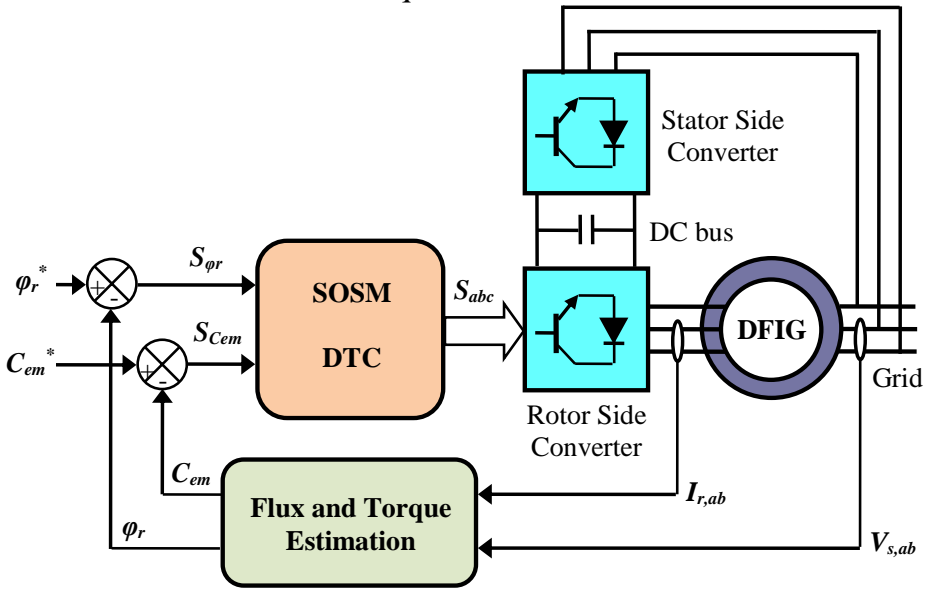

Fig. 2. Bloc diagram of the DFIG with SOSM-DTC

The main object of the control is to find an expression of the input $u=f(y, \dot{y})$ that be able to forces the trajectories of the system toward the beginning dot of the phase plane represented by $y=\dot{y}=0$, if feasible in restricted period of time. Input $u$ is supposed a new state variable, where the switching control is appended to its derived $\dot{u}$. Output $y$ is regulated by a SOSM controller. necessary to know the derivatives of the surface $\dot{S}, \ddot{S}, \ldots, S^{(n-1)}$ for performing an $\mathrm{n}^{\text {th }}$-order controller. Amid all algorithms used recently for the HOSM control, the supertwisting one is an exclusion. Indeed, this kind of algorithms needs just the information about $S$ [24]. Therefore, the super twisting algorithm has been employed in this paper. As presented in [25], for all SOSM controllers stability can be easily verified with this algorithm.

The bloc diagram of the DFIG control using SOSM-DTC is shown in figure 2 .

The SOSM controllers of rotor flux and electromagnetic torque are used to act successively on the two rotor voltage components as in (13) and (14) [20,33].

$$
\begin{aligned}
& V_{d r}=K_{1}\left|S_{\varphi r}\right|^{r} \operatorname{sign}\left(S_{\varphi r}\right)+V_{d r 1} \\
& \dot{V}_{d r 1}=K_{1} \operatorname{sign}\left(S_{\varphi r}\right) \\
& V_{q r}=K_{1}\left|S_{C e m}\right|^{r} \operatorname{sign}\left(S_{C e m}\right)+V_{q r 1} \\
& \dot{V}_{q r 1}=K_{2} \operatorname{sign}\left(S_{C e m}\right)
\end{aligned}
$$

Where the sliding mode variables are the flux magnitude error $S_{\varphi r}=\varphi_{r}{ }^{*}-\varphi_{r}$ and the torque error $S_{C e m}=C_{e m}{ }^{*}-C_{e m}$, and the control gains $K_{1}$ and $K_{2}$ should verify the terms of stability.

\section{A. Controller synthesis}

Suppose a dynamic system defined as follows:

$$
\frac{d x}{d t}=a(x, t)+b(x, t) u, \quad y=c(x, t)
$$

where $u$ is the input, $x$ is the variable state and $y$ is the output.

$$
\begin{aligned}
& u=K_{1}|S|^{r} \operatorname{sign}(S)+u_{1} \\
& \dot{u}_{1}=K_{2} \operatorname{sign}(S)
\end{aligned}
$$

Where $S=y^{*}-y$ is the sliding surface.

As indicated by expressions (16), the appropriate stipulation for convergence to $S$ that can verify stability is for the gains to be large sufficient [20]. 


$$
K_{1}>\frac{A_{M}}{B_{m}}, K_{2} \geq \frac{4 A_{M}}{B_{m}{ }^{2}} \cdot \frac{B_{M}\left(K_{1}+A_{M}\right)}{B_{m}\left(K_{1}-A_{M}\right)}
$$

Where $A_{M} \geq|A|$ and $B_{M} \geq B \geq B_{m}$ are the bigger and lower limits of $A$ and $B$ in the $2^{\text {nd }}$ derivative of the output $y$.

$$
\frac{d^{2} y}{d t^{2}}=A(x, t)+B(x, t) \frac{d u}{d t}
$$

\section{FuZZY SECOND ORDER SLIDING Mode DIRECT TORQUE CONTROL (FSOSM-DTC)}

SOSM control has proven in several studies and research applications its effectiveness in minimizing chattering effect which is mainly caused by the presence of a discontinuous control term containing the sign function [13-15]. To ameliorate the SOSM-DTC of the DFIG and more and more decrease the adverse effect caused by the sign function, in this work we suggest to employ a hybrid approach of second order sliding mode and fuzzy logic by replacing this function by an inference fuzzy system.

For the proposed FSOSM-DTC, the universes of discourses are first divided into the seven linguistic variables NB, NM, NS, EZ, PS, PM, PB, triangular and trapezoidal membership functions are chosen to represent the linguistic variables for the inputs and outputs of the controllers.

The fuzzy labels used in this study are negative big (NB), negative medium (NM), negative small (NS), equal zero (EZ), positive small (PS), positive medium (PM) and positive big (PB).

Figure 3 describes these choices.
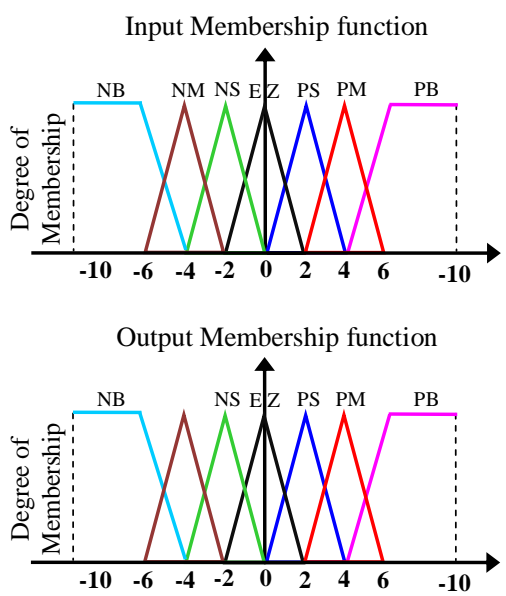

Fig. 3. Fuzzy sets and its memberships functions

\section{Simulation Results}

In order to evaluate the proposed DTC strategy of the DFIG, simulation tests using MATLAB Software have been realized and discussed in this section. The DFIG parameters used in simulations are as follows: nominal stator power $P_{s n}=$ $1.5 \mathrm{MW}, n_{p}=2, R_{s}=0.012 \Omega, R_{r}=0.021 \Omega, L_{s}=0.0137 \mathrm{H}, L_{r}$ $=0.0136 \mathrm{H}, M=0.0135 \mathrm{H}, F_{r}=0.0024 \mathrm{Nm} / \mathrm{s}, J=1000 \mathrm{~kg} \cdot \mathrm{m}^{2}$. C-DTC, SOSM-DTC and FSOSMC are evaluated by simulations regarding tracking performances, total harmonic distortion (THD) of stator current and robustness versus variation of machine parameters.

\section{A. Tracking performances}

This test has the goal to analyze and compare the behavior of the three used DTC control methods regarding tracking performances. The obtained simulation results are shown by figures 4-7. As it's shown by figures 4-6, electromagnetic torque and rotor flux curves for the three used DTC methods follows excellently their references. Furthermore, we observe that the FSOSM-DTC and SOSM-DTC strategies guarantee the decoupling between the $d$ and $q$ axes contrary to the CDTC where the coupling trace between them is somewhat clear. Otherwise, figure 7 illustrates the harmonic spectrums of the stator current for the three DTC control methods. Through this figure, it can be noticed that the total harmonic distortion (THD) is minimized for the SOSM-DTC method (THD = $1.31 \%)$ when compared to the C-DTC one (THD $=2.22 \%)$ and the THD is more and more reduced by using fuzzy logic (THD $=1.15 \%$ ). Based on the results above, it can be said that the FSOSM-DTC has proven its efficiency in reducing chattering phenomenon in addiction to keeping the same advantages of the SOSM-DTC scheme.

\section{B. Test of Robustness}

In order to examine the performances of the three DTC control methods regarding robustness against variation of machine parameters, these last have been deliberately modified as follows: the values of $R_{s}$ and $R_{r}$ are multiplied by 2 while the values of $L_{s}, L_{r}$ and $M$ are divided by 2 . The DFIG speed was kept equal to its face value. Figures 8-10 illustrate the obtained simulation results. These results show clearly that parametric variations test augment somewhat the time-response of the results obtained with C-DTC method. In addition, these results demonstrate that the parametric variations generate a visible influence on electromagnetic torque and rotor flux curves and that the influence seems more significant for the C-DTC compared to the other DTC schemes. Therefore, it can be concluded that the new proposed FSOSM-DTC scheme and in addition to its efficiency in reducing chattering phenomenon has kept the most important advantage of the SMC approach which is the robustness.

\section{CONCLUSION}

In this paper, a new DTC scheme of a doubly fed induction generator attached to the electric network through the stator part and fed by a back to back inverter by the rotor part has been discussed. Firstly, a modeling of a DFIG-based wind turbine has been presented. Frequently used in the WTSs, this generator presents several benefits such as variable speed function and the ability to work in the four quadrants. Secondly, a new DTC scheme using SOSM and fuzzy logic is synthesized and compared to both C-DTC and SOSM-DTC. In term of tracking performances electromagnetic torque and rotor flux curves for the three used DTC methods follows excellently their references, however a problem of coupling is emerged in the C-DTC curves that is removed with the other SOSM-DTC methods. Furthermore, the obtained results have approved that the FSOSM-DTC works with a lesser chattering effect. A test of robustness has also been elaborated in this paper where the machine parameters have been deliberately changed. After 
these variations, a few ripples have been induced on the curves of electromagnetic torque and rotor flux but with a significant influence with the C-DTC strategy compared to the other DTC methods. In light of the obtained results, one can conclude that the proposed FSOSM-DTC scheme represents an important tool for systems using DFIG such as WTSs.
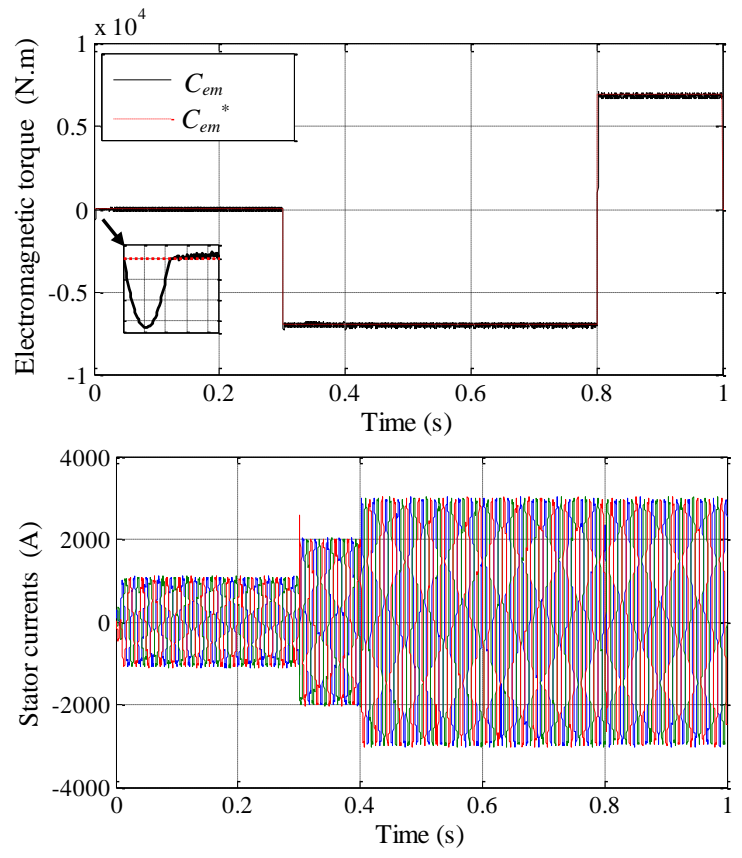

Fig. 4. C-DTC strategy responses (reference tracking test)
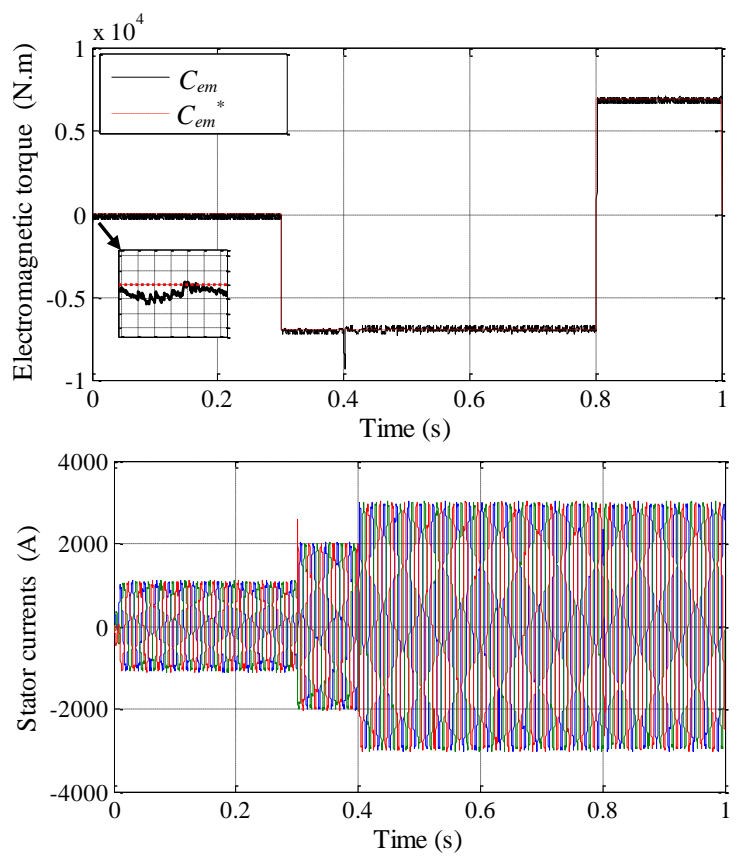

Fig. 5. SOSM-DTC strategy responses (reference tracking test)
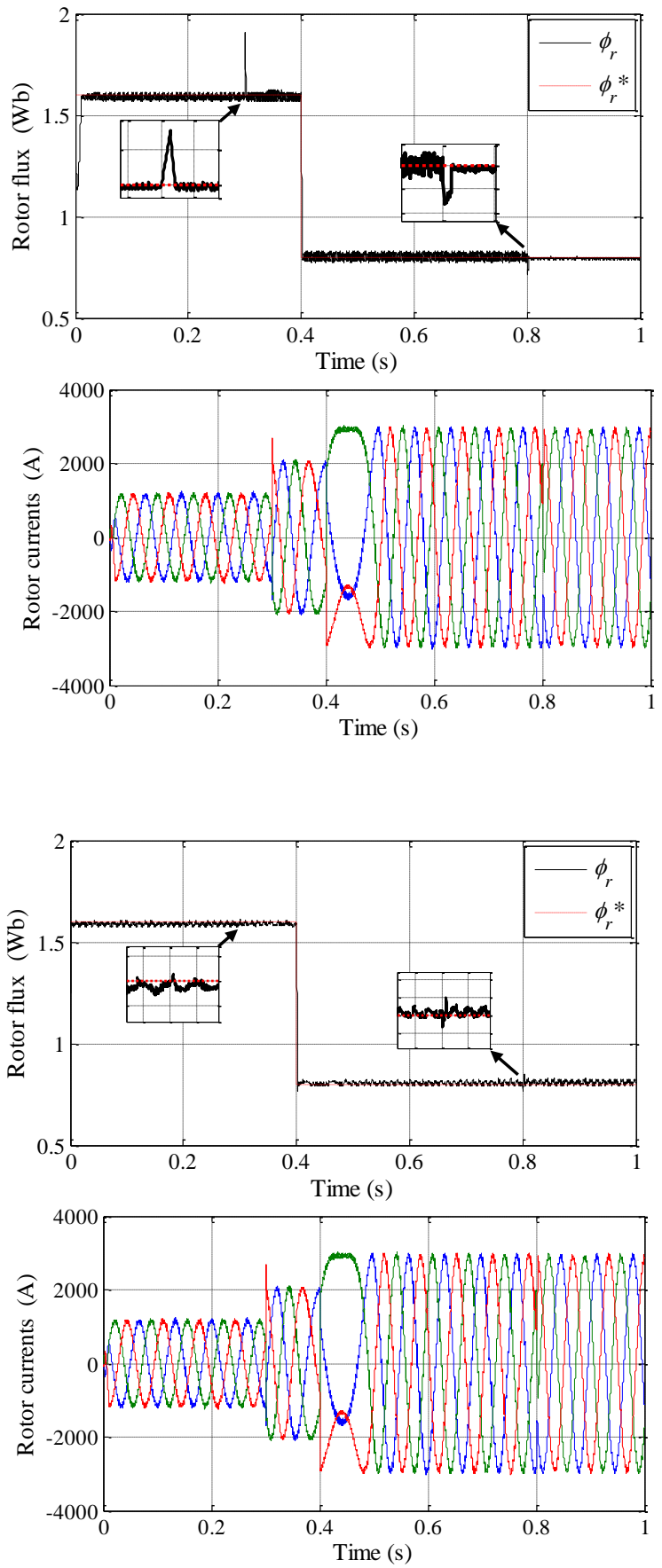

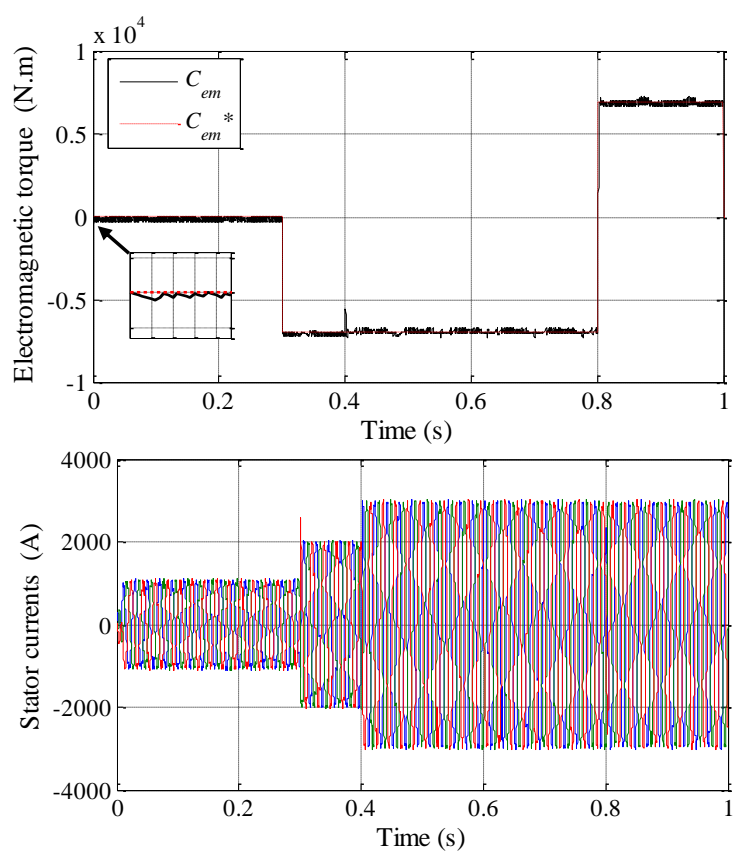

Fig. 6. FSOSM-DTC strategy responses (reference tracking test)

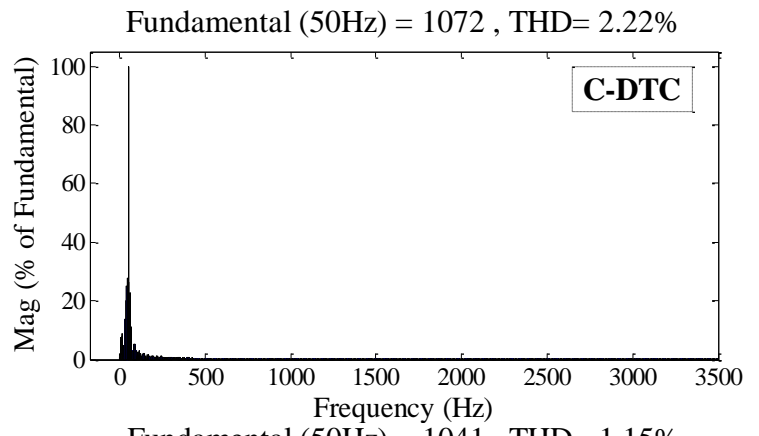

Fundamental $(50 \mathrm{~Hz})=1041, \mathrm{THD}=1.15 \%$

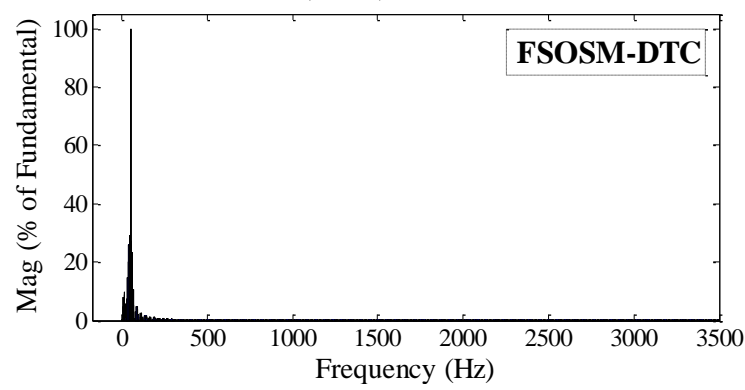

Fig. 7. THD of one phase stator current for a DFIG

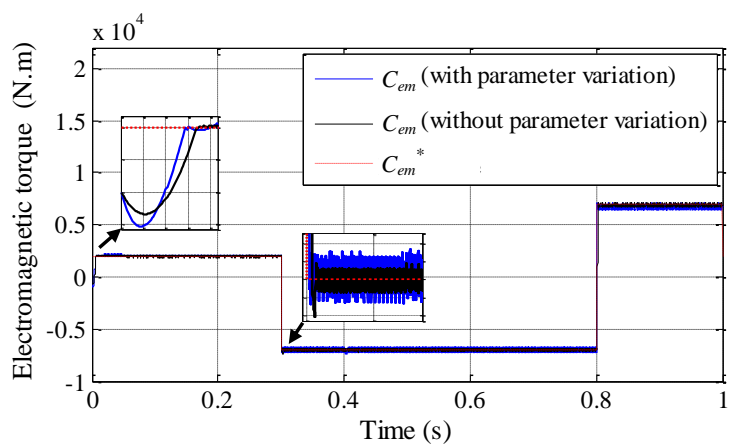

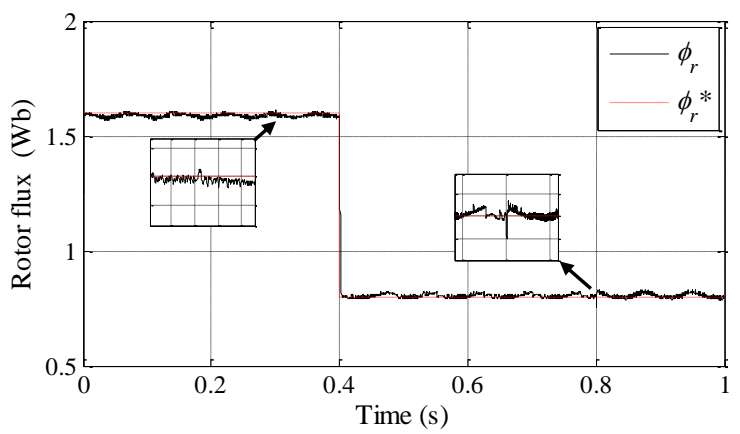
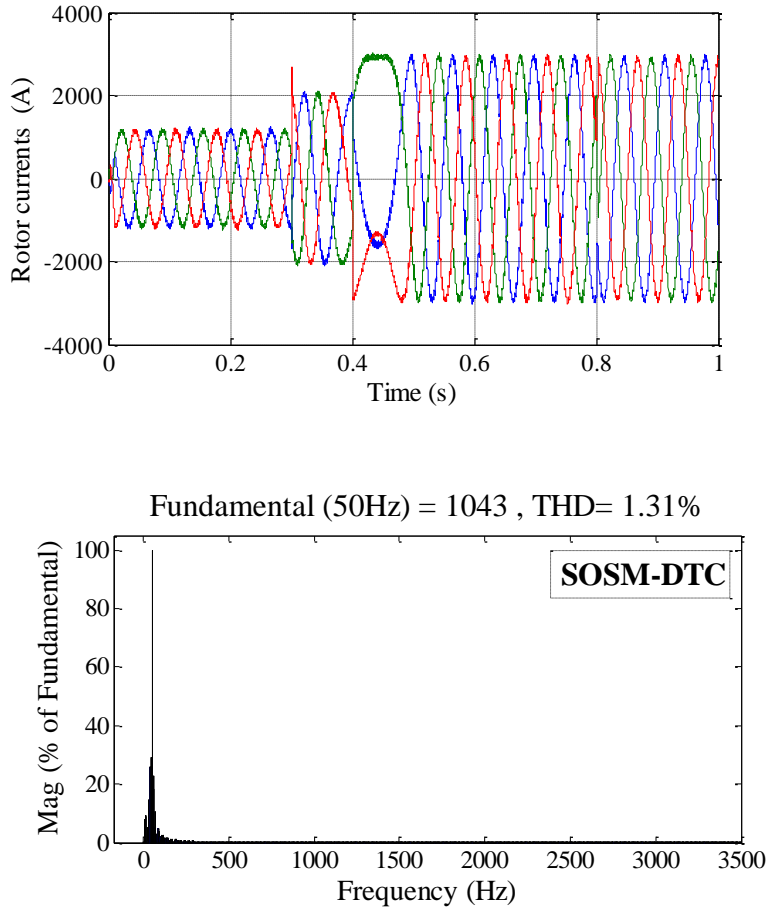
Fig. 8. C-DTC strategy responses (robustness test)
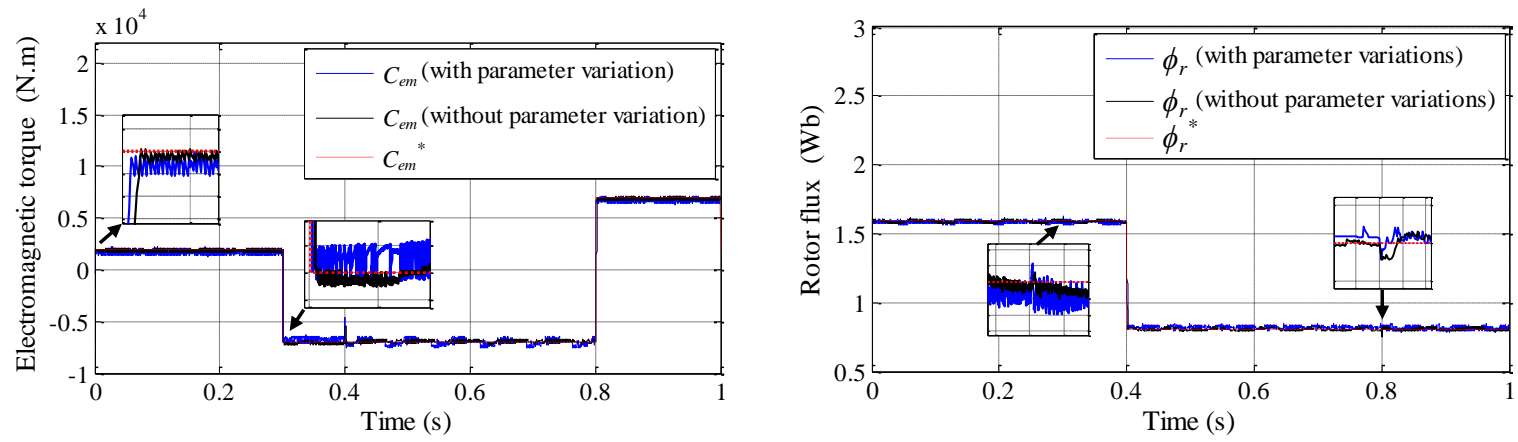

Fig. 9. SOSM-DTC strategy responses (robustness test)
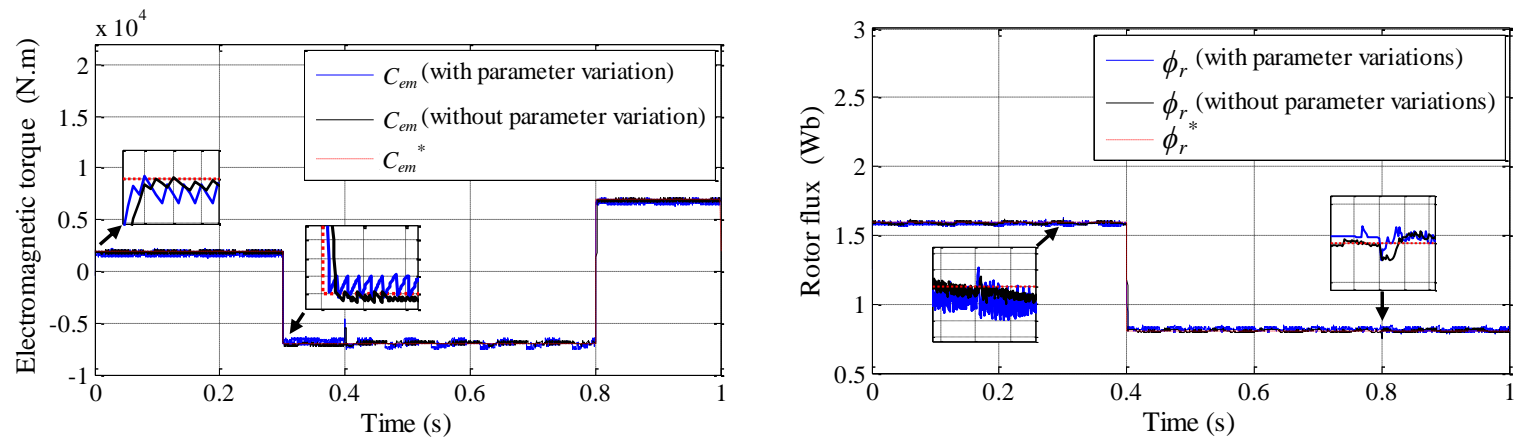

Fig. 10. FSOSM-DTC strategy responses (robustness test)
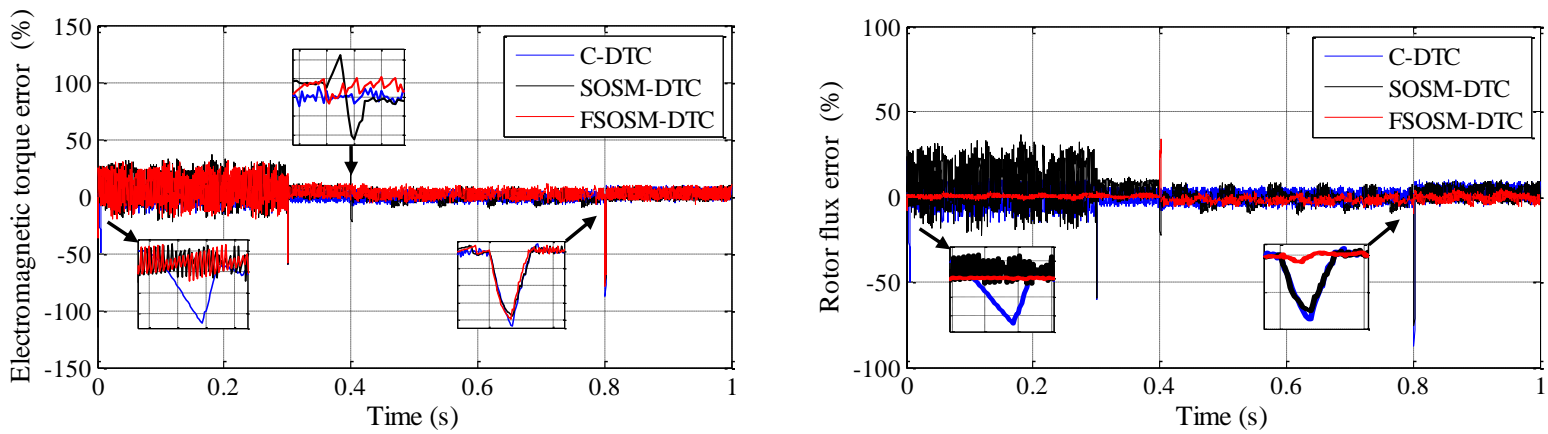

Fig. 11. Error curves (robustness test)

\section{REFERENCES}

[1] Lakhoua M.N., "Systemic Analysis of a Wind Power Station in Tunisia", Journal of Electrical and Electronics Engineering, ISSN: 1844-6035, University of Oradea Publisher, Vol. 4, N ${ }^{\circ} 1,2011$.

[2] M. Edrah, L.K. Lo, O. Anaya-Lara, "Impacts of high penetration of DFIG wind turbines on rotor angle stability of power systems," IEEE T Sustain Energ, Vol. 6, 2015, pp. 759-766.

[3] A.B. Ataji, Y. Miura, T. Ise, H. Tanaka "Direct Voltage Control With Slip Angle Estimation to Extend the Range of Supported Asymmetric Loads for Stand-Alone DFIG," IEEE T Power Electr, Vol. 31, No. 2, February 2016, pp. 1015-1025.

[4] A.M. Rao, N.K. Kumar, K. Sivakumar, "A multi-level inverter configuration for $4 \mathrm{n}$ pole induction motor drive by using conventional two-level inverters," In: IEEE 2015 International Conference on Industry Technology, 17-19 March 2015, Seville, Spain: IEEE. pp. 592-597.

[5] Y. Zhang, Z. Li, T. Wangy, W. Xuy, J. Zhuy, "Evaluation of a class of improved DTC method applied in DFIG for wind energy applications," In: IEEE 2011 International Conference on Electrical Machines and Systems, 20-23 August 2011, Beijing, China: IEEE. pp. 2037-2042.
[6] S.E. Ardjoun, M. Abid, "Fuzzy sliding mode control applied to a doubly fed induction generator for wind turbines," Turk J Elec Eng \& Comp Sci, Vlo. 23, 2015, pp. 1673-1686.

[7] X. Yao, Y. Jing, Z. Xing, "Direct torque control of a doubly-fed wind generator based on grey-fuzzy logic," In: International Conference on Mechatronics and Automation, Harbin, China, 2007. pp. 3587-3592.

[8] G.S. Buja, M.P. Kazmierkowski, "Direct torque control of PWM inverter-fed AC motors - a survey," IEEE T Ind Electron, Vol. 51, 2004, pp. 744-757.

[9] J. Holtz, "Pulse width modulation for electronic power conversion," $\mathrm{P}$ IEEE, Vol. 82, 1994, pp. 1194-1214.

[10] S.Z. Chen, N.C. Cheung, K.C. Wong, J. Wu, "Integral sliding-mode direct torque control of doubly-fed induction generators under unbalanced grid voltage," IEEE T Energy Conver, Vol. 25, 2010, pp. 356-368.

[11] X. Zhu, S. Liu, Y. Wang, "Second-order sliding-mode control of DFIGbased wind turbines," In: IEEE 2014 3rd Renewable Power Generation Conference, 24-25 September 2014, Naples, Italy: IEEE. pp. 1-6.

[12] M.A.A Morsy, M. Said, A. Moteleb, H.T. Dorrah, "Design and implementation of fuzzy sliding mode controller for switched reluctance 
motor, In: IEEE 2008 International Conference on Industrial Technology, 21-24 April 2008, Chengdu, China: IEEE. pp. 1367-1372.

[13] X. Yuan, Z. Chen, Y. Yuan, Y. Huang, "Design of fuzzy sliding mode controller for hydraulic turbine regulating system via input state feedback linearization method," Energy, Vol. 93, 2015, pp. 173-187.

[14] H.U. Rehman, R. Dhaouadi, "A fuzzy learning-sliding mode controller for direct field-oriented induction machines," Neurocomputing, Vol. 71, 2008, pp. 2693-2701.

[15] N. Ullah, W. Shaoping, M.I. Khattak, M. Shafi, "Fractional order adaptive fuzzy sliding mode controller for a position servo system subjected to aerodynamic loading and nonlinearities," Aerosp Sci Technol, Vol. 43, 2015, pp. 381-387.

[16] M. Van, H.J. Kang, Y.S. Suh, "A novel fuzzy second-order sliding mode observer controller for a T-S fuzzy system with an application for robot control," Int J Precis Eng Man, Vol. 14, 2013, pp.1703-1711.

[17] S. Mefoued, "A second order sliding mode control and a neural network to drive a knee joint actuated orthosis," Neurocomputing, Vol. 155, 2015, pp. 71-79.

[18] Z. Yan Z, C. Jin, V.I. Utkin, "Sensorless sliding-mode control of induction motors," IEEE T Ind Electron, Vol. 47, 2000, pp. 1286-1297.

[19] C. Lascu, I. Boldea, F. Blaabjerg, "Variable-structure direct torque control - A class of fast and robust controllers for induction machine drives," IEEE T Ind Electron, Vol. 51, 2004, pp. 785-792.

[20] C. Lascu, F. Blaabjerg, "Super-twisting sliding mode direct torque control of induction machine drives," In: IEEE 2014 Energy Conversion Congress and Exposition, 14-18 September 2014, Pittsburgh, PA: IEEE. pp. 5116-5122.

[21] S. Benelghali, "On multiphysics modeling and control of marine current turbine systems," PHD, Bretagne Occidentale University, France, 2009.

[22] G. Bartolini, A. Ferrara, E. Usani, "Applications of a sub-optimal discontinuous control algorithm for uncertain second order systems," Int J Robust Nonlin, Vol. 7, 1997, pp. 299-310.
[23] G. Bartolini, A. Ferrara, E. Usani, "Chattering avoidance by secondorder sliding mode control," IEEE T Automat Contr, Vol. 43, 1998, pp. 241-246.

[24] A. Levant, L. Alelishvili, "Integral high-order sliding modes," IEEE T Automat Contr, Vol. 52, 2007, pp. 1278-1282.

[25] A. Levant, "Higher-order sliding modes, differentiation and output feedback control," Int J Control, Vol. 76, 2003, pp. 924-941.

[26] S. Elaimani, "Modélisation de différentes technologies d'éoliennes intégrées dans un réseau de moyenne tension," $\mathrm{PhD}$, University of Lille, France, 2009.

[27] F. Poitier, T. Bouaouiche, M. Machoum, "Advanced control of a doublyfed induction generator for wind energy conversion," Electr Pow Syst Res, Vol. 79, 2009, pp. 1085-1096.

[28] A. Bakouri, A. Abbou, H. Mahmoudi, K. Elyaalaoui, "Direct torque control of a doubly fed induction generator of wind turbine for maximum power extraction," In: IEEE 2014 International Renewable and Sustainable Energy Conference, 17-19 October 2014; Ouarzazate, Morocco: IEEE. pp. 334-339.

[29] W.J. Wang, J.Y. Chen, "Passivity-based sliding mode position control for induction motor drives," IEEE T Energy Conver, Vol. 20, 2005, pp. 316-321.

[30] J.J.E. Slotine, "Sliding controller design for nonlinear systems," Int J Control, Vol. 40, 1984, pp. 421-434.

[31] B. Beltran, M.E.H. Benbouzid, T. Ahmed-Ali, "High-order sliding mode control of a DFIG-based wind turbine for power maximization and grid fault tolerance," In: IEEE 2009 International Electric Machines and Drives Conference, May 2009; Miami, Florida, USA: IEEE. pp. $183-$ 189.

[32] B. Beltran, M.H. Benbouzid, T. Ahmed-Ali, "Second-order sliding mode control of a doubly fed induction generator driven wind turbine," IEEE T Energy Conver, Vol. 27, 2012, pp. 261-269.

[33] S. Benelghali, M.E.H. Benbouzid, J.F. Charpentier, T. Ahmed-Ali, I. Munteanu, "Experimental validation of a marine current turbine simulator: Application to a PMSG-based system second-order sliding mode control," IEEE T Ind Electron, Vol. 58, 2011, pp. 118-126. 